\title{
Evaluating the Mechanical Properties of Fiber Yarns for Developing Synthetic Fiber Chains
}

\author{
Kyeongsoo Kim ${ }^{\circledR}$, Taewan Kim $\circledast^{2}$, Namhun Kim ${ }^{1}$, Dokyoun Kim $\oplus^{3}$, Yongjun Kang $\circledast^{3}$ and Seonjin Kim $\circledast^{2}$ \\ ${ }^{1}$ Senior Researcher, Special Ships Advanced Technology Center, Research Institute of Medium \& Small Shipbuilding, Busan, Korea \\ ${ }^{2}$ Professor, Department of Mechanical Engineering, Pukyong National University, Busan, Korea \\ ${ }^{3}$ Director, Technical Research Center, DSR. Corp., Busan, Korea
}

KEY WORDS: Fiber chain, Synthetic fiber, Stiffness, Time to rupture, Durability

\begin{abstract}
In this study, three types of synthetic fiber materials were evaluated, namely, DM20, SK78, and T147, to replace steel chains in shipbuilding and offshore fields with fiber chains as there is increasing demand for chains with lighter weights and improved usabilities. The strength and quasi-static stiffness were analyzed to select suitable yarns for the fiber chains. The durability of the yarn was evaluated by performing a 3-T (time to rupture) test as a specific tension level. The results of the experiment revealed excellent dynamic stiffness in DM20 and highest values of the windward and leeward stiffness in T147. 3-T linear design characteristic curves for a specific tension level were derived for the three types of fiber materials. The findings of this study can provide insights for improving strength and durability in fiber chain design.
\end{abstract}

\section{Introduction}

Link chains used in general industrial applications are formed by linking several steel rings, and these are used to connect a crane or winch for transporting heavy objects or lashing heavy objects to a designated location. Among the types of link chains, a load chain is representative, and for the field application of load chains, the wire diameter of the chain has to be increased according to the required load of application. However, in steel chains, as the wire diameter increases with increase in the working load, the weight of the chain increases in proportion; this compromises the workability and limits the application scope. Therefore, for using these chains in field applications, the weight of steel chains has to be reduced and the operation has to be made easier. These chains are subjected to high tension conditions during operation, such as gradual increase in the tensile force, peak load from external forces, and prolonged application of cyclic loading; therefore, these and various other load conditions should be considered in the research and development of fiber chains.

Steel is mostly used in industrial applications, but synthetic fiber has been used for a long time in mooring systems for ships and offshore structures. Among synthetic fiber chains used for lifting large loads, synthetic fiber ropes were first proposed for use as mooring lines in the 1960s, and since then, extensive studies have been conducted for practical use of synthetic fiber ropes (Banfield and Casey, 1998). Del Vecchio (1992) were the first to carry out systematic research on the mechanical behavior of polyester ropes. They examined the dynamic stiffness, creep, and fatigue behavior of polyester ropes; these are essential characteristics for application of polyester ropes in deepwater moorings. Petruska et al. (2010) installed the first offshore polyester mooring system in the Campos Basin, Brazil. Over time, polyester ropes have become the preferred option of mooring line installation up to a depth of $1500 \mathrm{~m}$. However, with increasing number of natural resources being discovered at increasing water depths, it remains to be explored whether polyester ropes can be utilized at these depths and whether they can provide sufficient stiffness to maintain adequate platform offsets (Davies et al., 2002). As the offshore oil and gas surveys moved to the deep seas, mooring with polyester ropes faced two challenges. The first problem is the size and weight of polyester ropes that are often considerably thick and long, which may exceed the allowable capacity of anchor handling boats and cause problems in installation (Chi et al., 2009; Det Norske Veritas, 2018). The second problem is that polyester ropes can have large elongations, which may lead to horizontal offsets exceeding the riser limit at depths of $>2000$ m (Fernandes et al., 1999).

Received 5 October 2021, revised 11 November 2021, accepted 15 November 2021

Corresponding author Seonjin Kim: +82-51-629-6163, sjkim@pknu.ac.kr

(C) 2021, The Korean Society of Ocean Engineers

This is an open access article distributed under the terms of the creative commons attribution non-commercial license (http://creativecommons.org/licenses/by-nc/4.0) which permits unrestricted non-commercial use, distribution, and reproduction in any medium, provided the original work is properly cited 
To address the limitations of the polyester material, ultra-highmolecular-weight polyethylene (UHMWPE), also known as highmodulus polyethylene (HMPE), was developed, and it has been widely applied as the most suitable material for deep-sea mooring lines. HMPE ropes are lighter than polyester ropes under equivalent minimum breaking load conditions and have smaller diameters and higher stiffnesses. Thus, HMPE ropes have technical as well as operational advantages over traditional polyester ropes for applications in deep-sea mooring (Peter et al., 2011; Davies et al., 2015). HMPE mooring systems with high stiffness are more riser friendly in terms of offset than polyester mooring lines, and HMPE ropes typically break at $2 \%-2.5 \%$ elongation after use when polyester ropes break at $12 \%-15 \%$ elongation. While the positions of offshore structures are held static, the waves apply a cyclic load on the mooring lines, which changes the fiber elongation, and thus, the mooring line is subjected to an extension-retraction fatigue load. In one study, an HMPE rope showed a longer fatigue life than a polyester rope with the same structure, and its axial compression fatigue properties were not inferior to those of an aramid fiber sample (Garrity and Fronzaglia, 2008, Leite and Boesten, 2011). A hybrid rope prepared as a combination of HMPE and polyester has been proposed for mooring systems located in storm and hurricane risk areas where rope stiffness and elasticity are required at the same time. Theoretical and numerical studies of polyester mooring lines for coupled dynamic analysis with deep-sea floating platforms have been conducted (Bunsell et al., 2009, S. Leite et al., 2011, Tahar and Kim, 2008).

The mechanical behavior of synthetic fiber ropes directly impacts mooring responses (Weller et al., 2014). Berryman et al. (2002) examined the residual strength of HMPE ropes for use in mooring lines of mobile offshore drilling units (MODUs) for 110 days; the results showed that the HMPE rope was still in good condition compared to the initial test specimen state. Williams et al. (2002) performed small-scale static tensile testing using polyester elements and sub-rope components to examine damaged ropes. Ward et al. (2006) conducted the length to diameter ratio effect tests on polyester ropes used for mooring to determine the effect of damage on their residual strengths and developed guidelines for mitigating damage in polyester rope mooring lines. Da Costa Mattos and Chimisso (2011) modeled creep tests of HMPE fibers used in ultra-deep-sea mooring ropes and compared the expected lifetime and elongation (\%) of the test specimens at various load levels and temperatures. Cedric et al. (2020) analyzed the extension load sensitivity characteristics of HMPE ropes according to the initial load change, and Gen el. al. (2021) conducted an experimental study on the dynamic stiffness of full-size HMPE ropes under long-term cyclic loading conditions.

Several studies have proposed polyester and HMPE as suitable materials for preparing synthetic fiber ropes for mooring and examined their applications. However, with fiber chains, strength and durability similar to mooring ropes are required to transport heavy objects; however, their usage and required characteristics vary than those of mooring ropes. Therefore, to select a suitable material for crane ropes, in this study, we aim to analyze the characteristics of HMPE and liquid crystal polymer (LCP) materials in terms of quasi-static stiffness and durability under various load conditions.

\section{Materials and Methods}

\subsection{Materials and Experimental Setup}

In this study, three types of fiber materials were tested for fiber chain development. Considering the yarn types with strength, durability, and wear resistance that can satisfy the specifications of fiber chain development, HMPE DM20, HMPE SK78, and LCP T147 were selected as test materials. The materials used in this study were supplied by DSR Corp. and the types of fiber materials used in this study and their mechanical properties are presented in Table 1.

Table 1 Types of fiber sample and their mechanical properties

\begin{tabular}{cccc}
\hline Type & $\begin{array}{c}\text { Modulus } \\
(\mathrm{g} / \mathrm{den})\end{array}$ & $\begin{array}{c}\text { Tenacity } \\
(\mathrm{g} / \text { den })\end{array}$ & $\begin{array}{c}\text { Elongation } \\
(\% \text { at break })\end{array}$ \\
\hline DM20 (HMPE) & 1042 & 35 & 3.6 \\
SK78 (HMPE) & 1267 & 40 & 3.5 \\
T147 (LCP) & 600 & 25.9 & 3.8 \\
\hline
\end{tabular}

A Shimadzu model AGS-X universal tensile testing machine was used to apply varying load conditions to the fiber chain yarns, and the experimental system used to measure the mechanical properties is shown in Fig. 1.

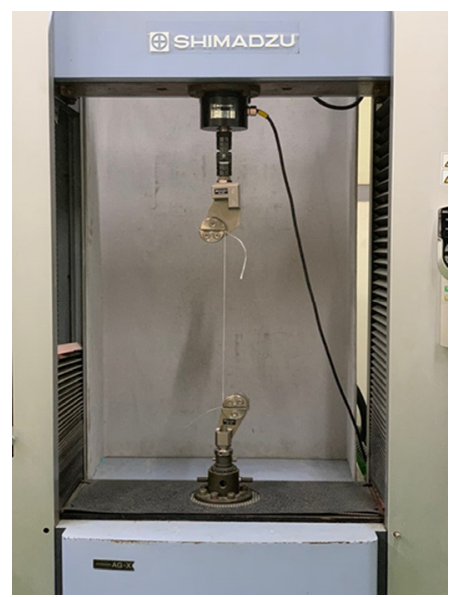

Fig. 1 Photograph of the physical property measurement

\subsection{Quasi-static Stiffness Test}

In field applications, fiber chains are subjected to repeated extension and retraction. During these extension-retraction loading cycles, the changes in the stiffness characteristics of the fiber chains are essential to ensure the durability of the fiber chains, and thus, analysis of the stiffness characteristics with respect to the type of yarn is necessary.

In typical applications, a lifting device such as fiber chains uses $50 \%$ or less of the mean breaking load (MBL). Therefore, it is necessary to set the cycle load conditions considering the general operating conditions of fiber chains; the conditions of quasi-static stiffness tests 
Table 2 Load cycle steps and load change conditions

\begin{tabular}{cccc}
\hline Cycle Step & Load cycle & Condition & Remark \\
\hline 1 & Extension load & $50 \%$ of YBL & \\
2 & Retraction load & $10 \%$ of YBL & 15 times \\
3 & Repetition & $10-30 \%$ of YBL & $24 \mathrm{~h}$ \\
4 & Extension load & $45 \%$ of YBL & $24 \mathrm{~h}$ \\
6 & Retraction load & $20 \%$ of YBL & $5 \%$ of YBL \\
\hline
\end{tabular}

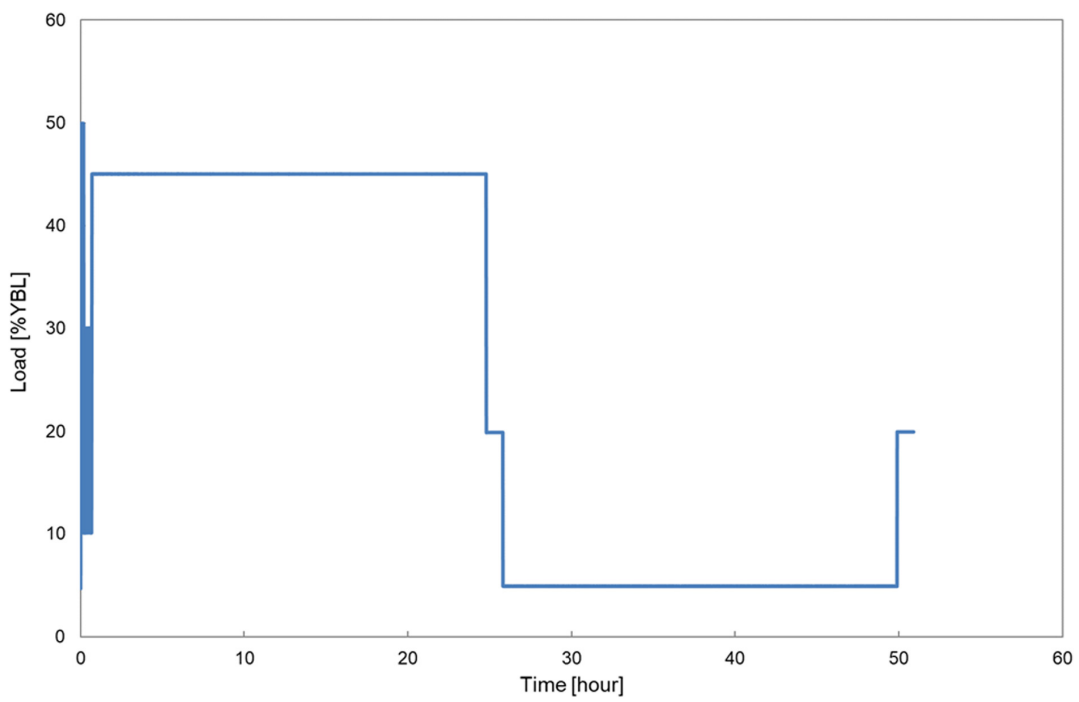

Fig. 2 Load change graph with time for quasi-static stiffness testing

reflecting the operating conditions are outlined in Table 2 and illustrated in Fig. 2.

The load cycles consist of cycle steps and load amplitudes, and in sequence of application, extension load was applied at $50 \%$ of MBL, retraction load at $10 \%$ of MBL; then, these cycles were repeated 15 times at $10-30 \%$ load range, and subsequently, extension load at $45 \%$ MBL, retraction load at $20 \% \mathrm{MBL}$, retraction load at $5 \%$ of MBL, and extension load at $20 \%$ MBL were applied (American Bureau of Shipping, 2020).

For evaluation of the yarn stiffness, quasi-static stiffnesses for windward and leeward conditions are measured in accordance with the test procedure. Windward stiffness is defined as the elongation (\%) change (including creep) between $20 \%$ and $45 \%$ yarn breaking load (YBL) over $24 \mathrm{~h}$, and leeward stiffness is defined as the change in elongation (\%) (including creep recovery) between 20\% and 5\% YBL over $24 \mathrm{~h}$. Yarn stiffness is calculated using Eq. (1):

$$
\text { Stiffness }=\frac{\triangle F / Y B L}{\triangle L / L_{i}}
$$

where $\triangle F$ represents the change in YBL considered in high- and low-load creep recovery, $\Delta L$ is the extensional displacement that occurs according to $\triangle F$, and $L_{i}$ represents the initial length at which the load cycle test starts.

\subsection{3-T Endurance Test}

When fiber chains are subjected to extension loads close to the design loads, the elongation (\%) increases and the fiber chain is eventually ruptured. In this regard, it is important to present the appropriate allowable tension, that is, the design load that the fiber chain can endure before rupture when the extension load is applied. Therefore, analysis of design loads is required for different fiber materials at the yarn level before they are fabricated into fiber chains. 3-T (tension vs. stretch test) endurance tests measure the time taken to rupture under stretched conditions of average breaking load (ABL) for design load analysis of different types of yarn.

3-T endurance tests were conducted in accordance with DNV rules (Det Norske Veritas, 2018) by applying extension loads with respect to the standard with reference to the mean breaking load (MBL); the time

Table 3 3-T endurance test condition

\begin{tabular}{ccc}
\hline Step & Load & Condition \\
\hline 1 & $1 \% \mathrm{ABL}$ & $17 \mathrm{~min}$ \\
2 & $1-50 \% \mathrm{ABL}$ & $10 \mathrm{cycles}$ \\
3 & $70 \% \mathrm{ABL}$ & \\
4 & - & Allow specimen to cool \\
5 & Load to designate tension & \\
6 & - & Measure the time to rupture \\
\hline
\end{tabular}


taken until the yarn was ruptured was measured. Table 3 outlines the conditions of the 3-T endurance tests.

\section{Results and Discussion}

\subsection{Quasi-static Stiffness According to Yarn Type}

Quasi-static stiffness tests were conducted using different types of yarn. Quasi-static stiffness is represented by the change in the strain in response to a change in the load. Strain change varies according to the extension and retraction, and the slope of the curve depends on the type of yarn. YBL was calculated based on the mean values of three measurements of the breaking load measurements of each yarn, and the breaking tensile strength results are listed in Table 4 . The average loading rate for static tensile strength test is $10 \% \mathrm{MBL} / \mathrm{min}$ (American Bureau of Shipping, 2020).

The measurement results for quasi-static stiffness of DM20 fiber (measured at $20^{\circ} \mathrm{C}$ conditions) are illustrated in Fig. 3. Before measuring the strain change over $24 \mathrm{~h}$, a load of $50 \% \mathrm{YBL}$, a retraction load of $10 \%$ YBL, and repeated loading of 10-30\% YBL were applied. For DM20 fiber, when $45 \%$ of MBL was applied for $24 \mathrm{~h}$, strain was increased by approximately $0.8 \%$. Since the load was applied for $24 \mathrm{~h}$, the characteristics of change in the creep behavior of the yarn are

Table 4 Yarn breaking test results

\begin{tabular}{ccc}
\hline Type & $\begin{array}{c}\text { Mean breaking load } \\
(\mathrm{N})\end{array}$ & $\begin{array}{c}\text { Tensile strength } \\
(\mathrm{N} / \text { tex })\end{array}$ \\
\hline DM20 & 485.2 & 2.757 \\
SK78 & 496.3 & 2.256 \\
T147 & 386.6 & 2.315 \\
\hline
\end{tabular}

included in the analysis. In addition, when a retraction load of $5 \%$ MBL was applied for $24 \mathrm{~h}$, strain recovery of $0.31 \%$ was obtained, and the characteristics of the change in the creep recovery behavior of the yarn were analyzed. Quasi-static windward stiffness is the slope of the load-strain curve, and it can be obtained when the load of the test conditions is applied; the windward stiffness of DM20 fiber was 18.1. Quasi-static leeward stiffness is the slope of the load-strain curve, and it is obtained when the retraction load of the test condition is applied; the leeward stiffness of DM20 fiber was 15.36. Dynamic stiffness is the slope of the load-strain curve, and it is obtained when the extension load-retraction load of the test condition is repeatedly applied; the dynamic stiffness of DM20 fiber was 51.82.

The results of measurements of quasi-static stiffness of SK78 fiber are shown in Fig. 4. From the test results of SK78, when 45\% MBL was applied for $24 \mathrm{~h}$, the strain increased by approximately $1.26 \%$, and when a retraction load of 5\% MBL was applied for $24 \mathrm{~h}$, a strain recovery of $0.57 \%$ was obtained. The quasi-static windward stiffness under extension load conditions and the leeward stiffness under retraction load conditions for SK78 fiber were 11.11 and 8.77, respectively, and the dynamic stiffness under the cyclic application of extension-retraction load was 38.46 .

The measurement results for quasi-static stiffness of T147 fiber (measured at room temperature conditions) are shown in Fig. 5. For $\mathrm{T} 147$, when $45 \% \mathrm{MBL}$ was applied for $24 \mathrm{~h}$, the strain increased by approximately $0.1 \%$, and when a retraction load of $5 \%$ was applied for $24 \mathrm{~h}$, strain recovery of $0.163 \%$ was obtained. The quasi-static windward stiffness under the extension load condition and the leeward stiffness under the retraction load condition for T147 fiber were 29 and 33.5 , respectively, and the dynamic stiffness under the cyclic application of extension-retraction load was 24.87 .

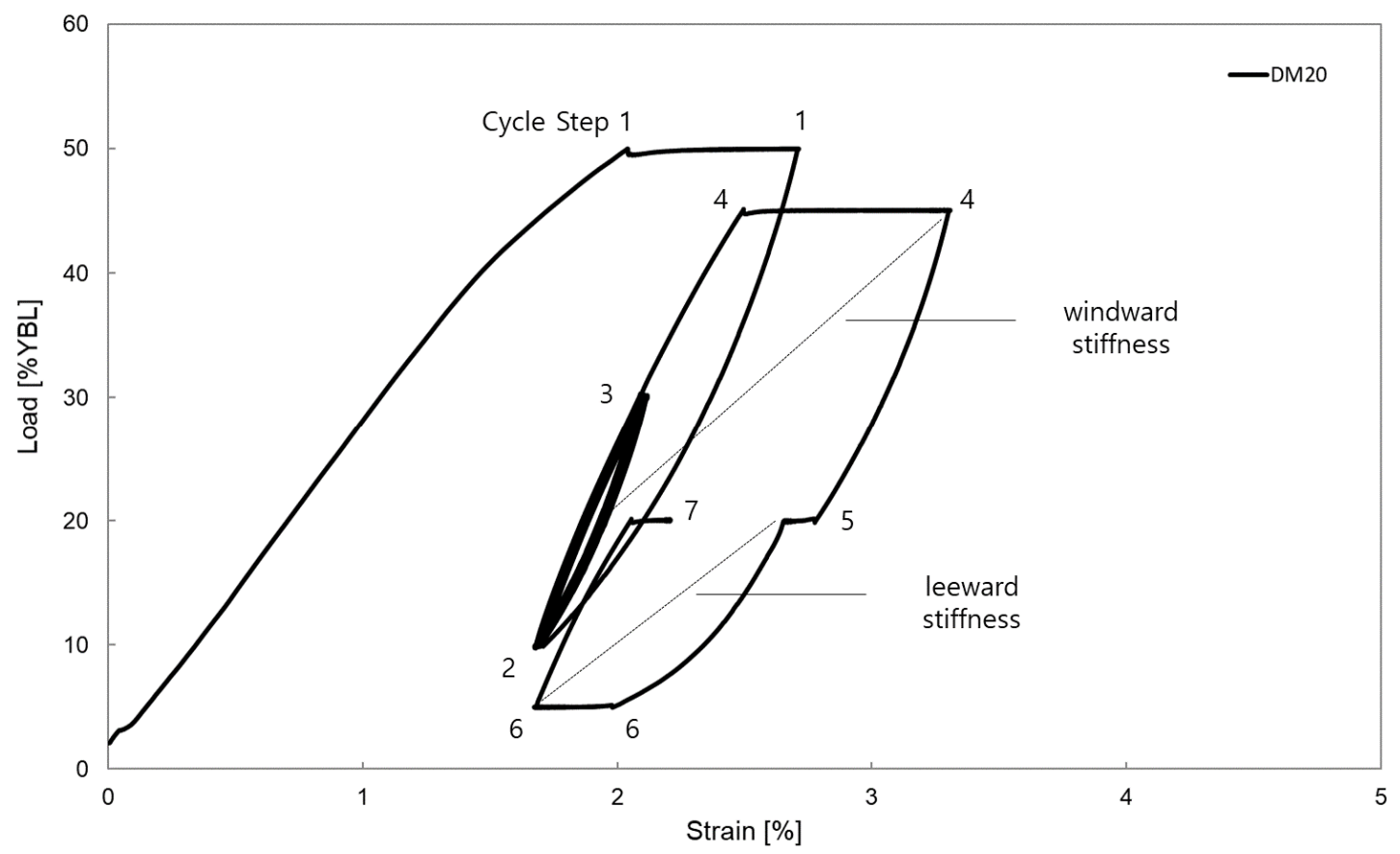

Fig. 3 Load-strain measured on DM20 fiber, based on yarn breaking load 


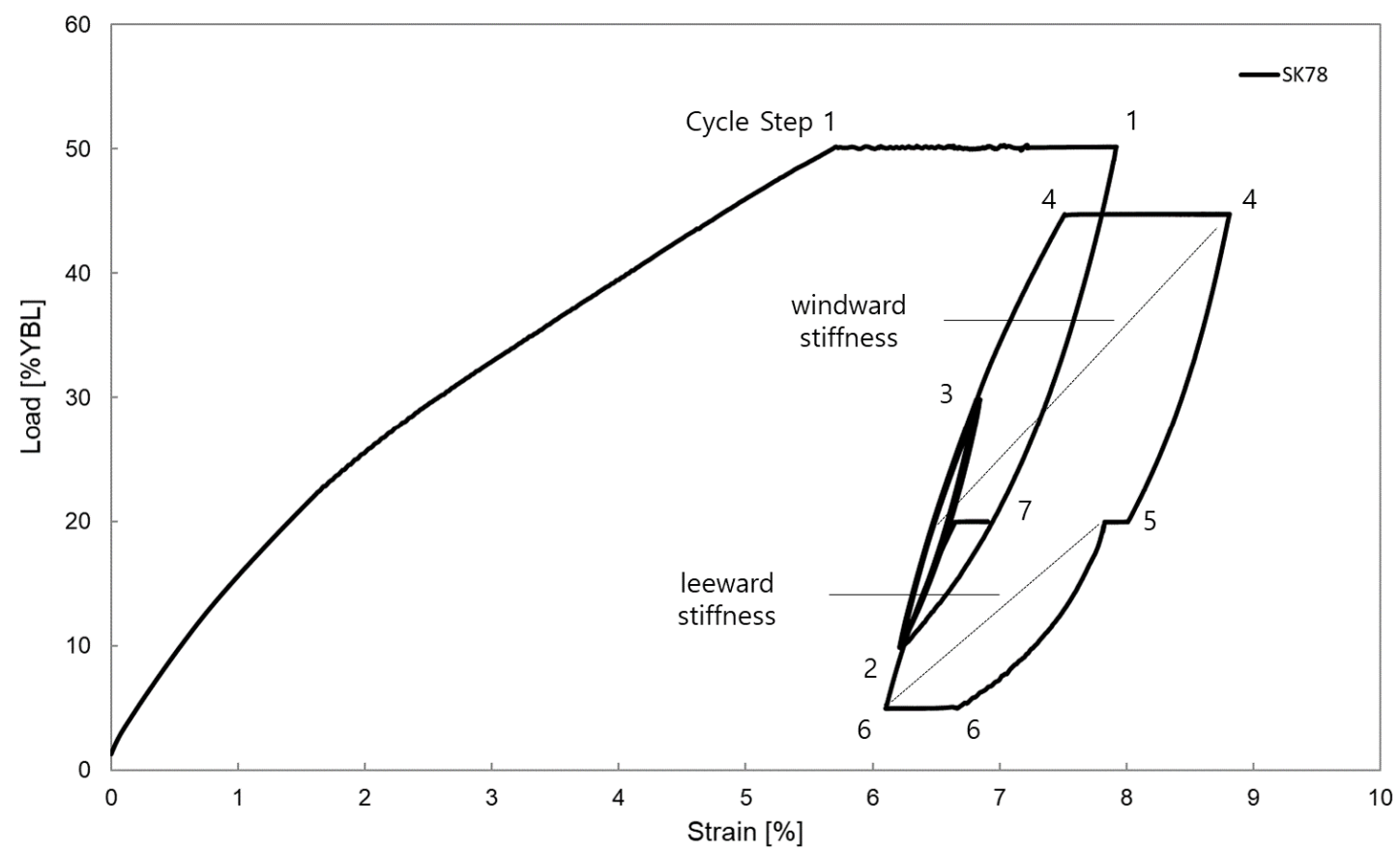

Fig. 4 Load-strain measured on SK78 fiber, based on yarn breaking load

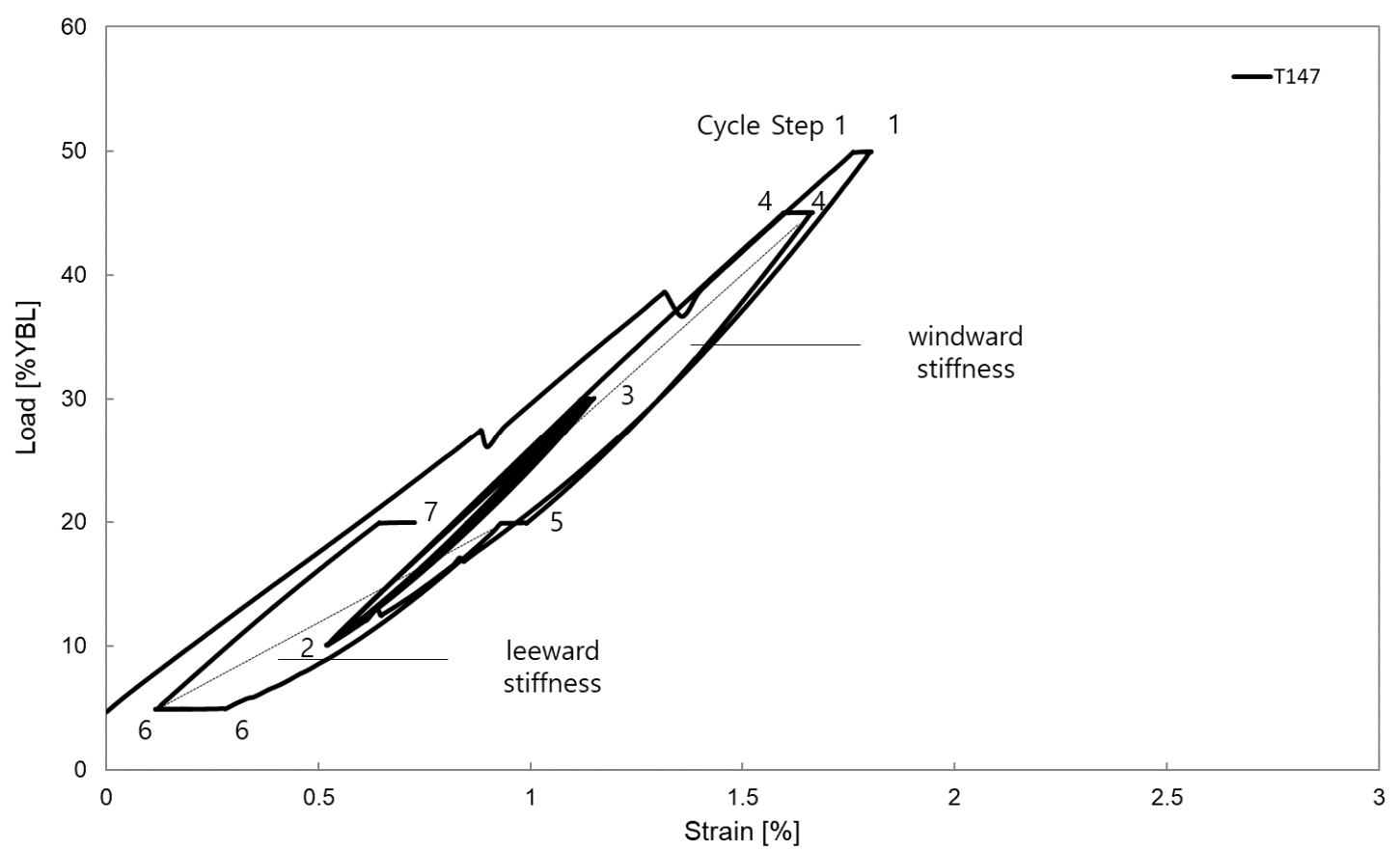

Fig. 5 Load-strain measured on T147 fiber, based on yarn breaking load

During field operations, fiber chains are subjected to high loads for prolonged durations. We applied $45 \% \mathrm{MBL}$ for $24 \mathrm{~h}$ or a retraction load of $5 \%$ for $24 \mathrm{~h}$ to simulate the type of environment during field operations; there is a difference in the behavior of strain change due to the difference in the viscoelastic behavior of the fibers. When extension load was applied for $24 \mathrm{~h}$, SK78 fiber showed the greatest strain increase among the three materials, showing a difference of approximately 12.6 times that of T147 fiber. The strain against the prolonged application of the extension load can be seen as representing the resistance characteristics of the fiber material under the conditions of continuous loading. The fiber ruptured when the maximum strain was exceeded; therefore, the fiber chain should exhibit less increase in the strain under continuous loading and excellent fatigue life.

Table 5 shows the increase in the strain with respect to the material under the conditions of continuous loading for $24 \mathrm{~h}$. When retraction load was applied for $24 \mathrm{~h}$, SK78 fiber, which showed a large increase in the strain against the extension load, exhibited the greatest strain recovery, and T147 fiber showed the smallest strain recovery. The strain against the prolonged application of the retraction load shows the characteristics of the recovery of the fiber material when the load is 
Table 5 Strain increase and recovery test results for 24 hours

\begin{tabular}{lccc}
\hline & DM20 & SK78 & T147 \\
\hline Strain increase at 45\% YBL & 0.8 & 1.26 & 0.1 \\
Strain recovery at 5\% YBL & 0.31 & 0.57 & 0.163 \\
\hline
\end{tabular}

Table 6 Equivalent stiffness and dynamic stiffness test results

\begin{tabular}{|c|c|c|c|}
\hline Stiffness & DM20 & SK78 & T147 \\
\hline $\begin{array}{l}\text { Windward stifness } \\
(24 \mathrm{~h} \text { at } 45 \% \text { YBL) }\end{array}$ & $18.1 \times \mathrm{YBL}$ & $11.11 \times \mathrm{YBL}$ & $29 \times \mathrm{YBL}$ \\
\hline $\begin{array}{l}\text { Leeward stifness } \\
(24 \mathrm{~h} \text { at } 5 \% \mathrm{YBL})\end{array}$ & $15.36 \times \mathrm{YBL}$ & $8.77 \times \mathrm{YBL}$ & $33.5 \times \mathrm{YBL}$ \\
\hline $\begin{array}{c}\text { Dynamic stiffness } \\
(10-30 \% \text { YBL })\end{array}$ & $51.82 \times \mathrm{YBL}$ & $38.46 \times \mathrm{YBL}$ & $24.87 \times \mathrm{YBL}$ \\
\hline
\end{tabular}

removed from the fiber chain. When a fiber chain is subjected to repeated load cycles such as extension-retraction-stop, the increase in the strain is accumulated, eventually leading to the breaking of the fiber, and therefore, it is essential to examine the characteristics of the fiber in terms of extension-recovery under the conditions of prolonged loading.

The calculated windward and leeward stiffnesses are presented in Table 6 . The calculated stiffness value corresponds to the slope in the load-strain graph, and the slope can be considered as the ratio of load change to strain change. A large slope indicates that the strain change was small even when the load change was large, and a small slope indicates that the strain change was large when the load change was large. Thus, T147 fiber showed the largest values of windward and leeward stiffnesses, and it is considered that T147 exhibited the smallest strain change under continuous load. For dynamic stiffness,
DM20 fiber showed the highest value (51.82). Under the repeated application of extension load-retraction load, the stiffness of DM20 fiber is excellent, and it is considered that DM20 had the longest lifetime under the described operating conditions.

\subsection{3-T Results of 3-T Endurance Test}

The 3-T endurance test measures the duration for which a test specimen retains a specific tension level, although the tension level is lower than the minimum breaking tensile strength. Since the time measured in this test can be set as a design curve for durability, the results and analysis of 3-T endurance test are essential.

3-T tests were conducted for each of the three types of yarn; the mean of $\log$ (time-to-rupture (TTR)) with respect to the tension level is presented in Table 7. At the minimum load level, DM20 fiber showed the highest mean TTR, and at the maximum tension level, T147 fiber had the highest mean TTR. The standard deviation of TTR by yarn type was 0.134 for DM20 and 0.208 and 0.102 for SK78 and T147,

Table 7 Means of $\log (\mathrm{s})$ time for tension level

\begin{tabular}{ccc}
\hline Type & Tension $(\mathrm{N} /$ tex $)$ & Mean \\
\hline \multirow{2}{*}{ DM20 } & 2.671 & 3.74 \\
& 2.757 & 2.78 \\
& 2.842 & 1.55 \\
SK78 & 2.185 & 3.50 \\
& 2.256 & 2.71 \\
& 2.326 & 1.01 \\
T147 & 2.242 & 3.62 \\
& 2.315 & 3.30 \\
\hline
\end{tabular}

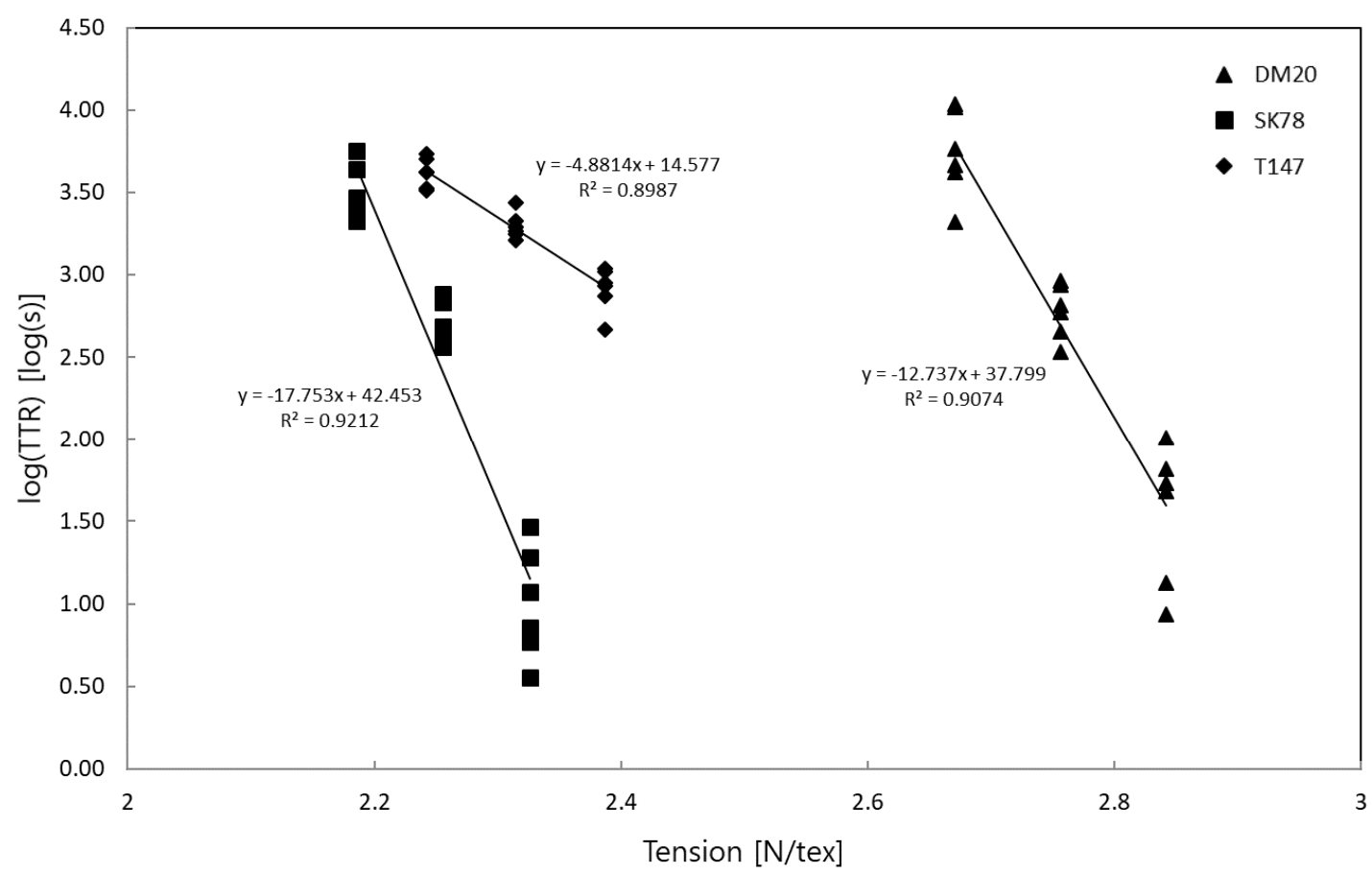

Fig. 6 Time to rupture test results with linear trend line added 
respectively, and the deviation of TTR showed an increasing trend with increase in the tension level.

Fig. 6 shows the results of the slope of the linear curve obtained in the test. As the tension decreased, TTR increased exponentially; therefore, TTR was expressed on a log scale. It was measured at three different tension levels for each type of yarn, and a linear trend line was obtained for the measurement results. A linear regression model was applied to easily predict the relationship of TTR to the tension level within the design range, and a linear trend line was derived using the least squares method. The linear trend line indicates the slope characteristic of TTR with respect to tension. The slopes of DM20, SK78, and T147 fibers were $-12.73,-17.75$, and -4.88 , respectively. Using the linear trend line values obtained from the test, the 3-T design characteristic curve that represents the design load characteristics with respect to time can be obtained. DM20 fiber exhibited a higher strength for the same lifetime, but examining the slope of the linear trend line, SK78 fiber showed the least decrease in the strength with respect to the increase in TTR.

In addition, the slope of the linear trend line indicates the tension with respect to the TTR, and TTR varies depending on the type of yarn material and the design load, which can provide insights for selecting the design strength of the yarn when fabricating the fiber chain. When the design strength of the yarn was decreased, the fatigue life increased with respect to the slope of the 3-T design characteristic curve, and therefore, the increase in the fatigue life can be predicted according to the slope calculated based on the test results.

\section{Conclusion}

In this study, to substitute the material used in steel chains with a synthetic fiber, the quasi-static stiffness characteristics of HMPE DM20, HMPE SK78, and LCP T147 fiber were analyzed, and 3-T endurance tests were performed. The results of this study are outlined as follows.

In the quasi-static stiffness test, the change in the strain of the fiber material against the application of the load is represented in terms of the value of the elastic properties of the fiber material under the conditions of prolonged application of extension load, retraction load, or continuous cyclic loads. With the fiber material, when non-cyclic loading was applied, such as extension-retraction loading, the increase in the strain accumulated, and when the maximum strain was exceeded, the fiber ruptured physically. Therefore, to obtain fiber chains with the desired characteristics, small increases in the strain are required under repeated extension-retraction loading and prolonged extension loading, and a large increase in the strain is required under the application of retraction loading. That is, when the quasi-static stiffness is large, the strain change with respect to the load is small; this characteristic is advantageous in terms of the durability of the fiber chain. In addition, the values of quasi-static windward, leeward, and dynamic stiffnesses of DM20, SK78, and T147 were calculated. T147 fiber showed the highest values for quasi-static windward and leeward stiffnesses, and DM20 fiber was excellent for dynamic stiffness.

For the three types of fiber materials, a 3-T design characteristic curve representing the tension-TTR relationship was derived. The decrease in the tension level and TTR varied depending on the type of the yarn material, and this characteristic can be applied as an important factor in selecting the design strength of the yarn when designing the fiber chain.

The 3-T design characteristic curve can be expressed as the ratio of tension to TTR, and the slope of the test result has important implications. DM20 showed high strength for the same lifetime, but from the slope of the 3-T design characteristic curve, SK78 fiber was calculated to show the lowest decrease in strength with respect to the increase in TTR. The increase in TTR with the decrease in the strength of the yarn can be predicted according to the slope calculated from the test results, which is an important factor in selecting the design strength of the yarn when fabricating the fiber chain.

It is expected that the results of the analysis of the quasi-static stiffness and 3-T design characteristic curve of different types of yarn can be utilized as important data for strength and durability characteristics in fiber chain design.

\section{Conflict of Interest}

No potential conflict of interest relevant to this article was reported.

\section{Funding}

This research was supported by the Ministry of Trade, Industry \& Energy (MOTIE) of Korea (S2641260).

\section{References}

Banfield, S., \& Casey, N. (1998). Evaluation of Fiber Rope Properties for Offshore Mooring. Ocean Engineering, 25(10), 861-79. https://doi.org/10.1016/S0029-8018(97)10017-8

Del Vecchio, C.J.M. (1992). Light Weight Materials for Deep Water Moorings (Ph.D. Thesis). University of Reading, UK.

Petruska, D.J., Kelly, P., Stone, B., Ahjem, V., Zimmerman, E.H., Garrity, R., \& Veselis,Y. (2010). Fiber Moorings, Recent Experiences and Research: Updating API RP 2SM on Synthetic Fiber Rope for Offshore Moorings. Offshore Technology Conference, Houston, USA. https://doi.org/10.4043/20836-MS

Davies, P., Francois, M., Grosjean, F., Baron, P., Salomon, K., \& Trassoudaine, D. (2002) Synthetic Mooring Lines for Depths to 3000 Meters. Offshore Technology Conference, Houston, USA. https://doi.org/10.4043/14246-MS

Chi, C.H., Lundhild, E.M., Veselis, T., \& Huntley, M. (2009) Enabling Ultra-Depwater Mooring with Aramid Fiber Rope Technology. Offshore Technology Conference, Houston, USA. https://doi. org/10.4043/20074-MS 
Det Norske Veritas. (2018) Offshore Fibre Ropes (Offshore Standard DNV-OS-E303).

Fernandes, A.C., Del Vecchio, C.J.M., Castro, G.A.V. (1999). Mechanical Properties of Polyester Mooring Cables. International Journal of Offshore and Polar Engineering, 9(3), 208-213.

Peter, D., Yvan, R., Loic, D., \& Patrice, W. (2011). Mechanical Behaviour of HMPE and Aramid Fibre Ropes for Deep Sea Handling Operations. Ocean Engineering, 38(17-18), 222082214. https://doi.org/10.1016/j.oceaneng.2011.10.010

Davies, P., Francois, M., Lacotte, N., Vu, T.D., \& Durville, D. (2015) An Empirical Model to Predict the Lifetime of Braided HMPE Handling Ropes Under Cyclic Bend Over Sheave (CBOS) Loading. Ocean Engineering, 97, 74-81. https://doi.org/10.1016/ j.oceaneng.2015.01.003

Garrity, R., \& Fronzaglia, W. (2008) The Use of HMPE Mooring Lines in Deepwater MODU Mooring Systems. In OCEANS 2008, IEEE, 1-4. https://doi.org/10.1109/OCEANS.2008.5151912.

Leite, S., \& Boesten, J. (2011) HMPE Mooring Lines for Deepwater MODUs. Offshore Technology Conference, Brazil. https:// doi.org/10.4043/22486-MS

Bunsell, A.R. (2009). Handbook of Tensile Properties of Textile and Technical Fibres, Woodhead Publishing.

Tahar, A., \& Kim, M.H. (2008). Coupled-Dynamic Analysis of Floating Structures with Polyester Mooring Lines. Ocean Engineering, 35(17-18), 1676-1685. https://doi.org/10.1016/ j.oceaneng.2008.09.004

Weller, S.D., Davies, P., Vickers, A.W., \& Johanning, L. (2014) Synthetic Rope Responses in the Context of Load History: Operational Performance. Ocean Engineering. 83, 111-124. https://doi.org/10.1016/j.oceaneng.2014.03.010

Berryman, C.T., Dupin, R.M., \& Gerrits, N.S. (2002) Laboratory Study of Used HMPE MODU Mooring Lines. Offshore Technology Conference, Houston, USA. https://doi.org/10.

\section{3/14245-MS}

Williams, J.G., Miyase, A., Li, D.H., \& Wang, S.S. (2002) Small-Scale Testing of Damaged Synthetic Fiber Mooring Ropes. Offshore Technology Conference, Houston, USA. https://doi.org/10. 4043/14308-MS

Ward, E.G., Ayres, R.R., Banfield, S.J., O’Hear, N., \& Laurendine, T. (2006) The Residual Strength of Damaged Polyester Ropes. Offshore Technology Conference, Houston, USA. https:// doi.org/10.4043/18150-MS

Da Costa Mattos, H.S., \& Chimisso, F.E.G. (2011) Modelling Creep Tests in HMPE Fibres Used in Ultra-Deep-Sea Mooring Ropes. International Journal Of Solids And Structures. 48(1), 144-152. https://doi.org/10.1016/j.ijsolstr.2010.09.015

Cédric, B., Peter, D., Guilhem, B., Yann, M., \& Julien, B. (2020) Influence of Bedding-in on the Tensile Performance of HMPE Fiber Ropes. Ocean Engineering, 203, 107144. https://doi.org/ 10.1016/j.oceaneng.2020.107144

Gen, L., Wenhua, L., Shanyin, L., Hangyu, L., Yangyuan, G., \& Yuqing, S. (2021) Dynamic Stiffness of Braided HMPE Ropes Under Long-Term Cyclic Loads: A Full-Scale Experimental Investigation. Ocean Engineering. 230, 109076. https://doi.org/ 10.1016/j.oceaneng.2021.109076

American Bureau of Shipping. (2020) Guidance Notes on The Application of Fiber for Offshore Mooring.

\section{Author ORCIDs}

Author name
Kim, Kyeongsoo
Kim, Taewan
Kim, Namhun
Kim, Dokyoun
Kang, Yongjun
Kim, Seonjin

ORCID

0000-0003-3429-8063

$0000-0001-7464-3752$

$0000-0003-1884-938 \mathrm{X}$

$0000-0002-8946-9483$

$0000-0001-8964-7916$

$0000-0001-7755-2581$ 